\title{
THE IMPORTANCE OF SEARCH ENGINE OPTIMIZATION ON DIFFERENT LANGUAGES FOR SAAS BUSINESSES
}

\author{
Rodica Bogdan 9 \\ Jeanine Naomi Bogdan 10 \\ Ioana Claudia Horea ${ }^{11}$
}

https://doi.org/10.31410/itema.2018.26

\begin{abstract}
Google has become an important part of the business world nowadays. Since more and more companies are digital, the market that we used to know before has now suffered severe transformations. This is, definitely, not a bad thing, but businesses that want to survive have to keep up with the fast pace that characterizes the business world. If previously the market place was a physical space, now search engines have taken their role. The higher you rank, the more are the chances that people will choose your business to fulfill their intent. Globalization comes as a decisive factor in the equation of visibility for a business, and the variety of markets and their relevance can be considered key players in this hierarchy. Search engine optimization (SEO) comes now as a must. It is of utmost importance for a business to have a strong site but it is also essential that it is well optimized, adequately prepared to meet the users' needs, directly and effectively. A first step in getting a competitive edge now is to be user centered, to focus on the customers' current as well as future needs. In order to stay on the market, businesses have to keep up with technology and need to be innovative and intuitive, anticipating the direction of the market. For instance, because words that are much valid and market effective in one country are simply not selling in another, Software as Service businesses (SaaS) has been compelled to optimize on various languages. Canva is one example of such optimization. As their market is Google, SaaS depend extensively on their success in affecting the online visibility of a website in the search engine's results.
\end{abstract}

Keywords: market efficiency, online search, language optimization, business website, search engine optimization, SaaS businesses.

\section{INTRODUCTION}

$\mathrm{T}$ The emergence of the Internet in 1990 had a definite impact on the way people communicate and interact. The Internet provides the most effective communication channels among people, including emails and instant messages. The evolution of technology and the speed of information circulation have radically affected the business world and the consumer behavior.

Together with the Internet, globalization has played a key role in business development. The expansion of telecommunication systems has enabled companies and other organizations to start operating at an international scale. Globalization allowed companies to be more competitive and effective, they can become very profitable, but global competition can be

\footnotetext{
${ }^{9}$ Faculty of Economic Sciences, University of Oradea, str.Universității nr.1, Romania

${ }^{10}$ Faculty of Economic Sciences, University of Oradea, str.Universității nr.1, Romania

${ }^{11}$ Faculty of Economic Sciences, University of Oradea, str.Universității nr.1, Romania
} 
challenging as well. You can be very profitable, but you can also fall down harshly; there's a thin line in this respect in the current business environment.

If in the past the Industrial Revolution consisted in mechanizing the processes to achieve mass production, today the successful companies are those who know how to automate production by using electronics and information technology.

\section{SOFTWARE-AS-A-SERVICE BUSINESS MODEL}

Software-as-a-Service (SaaS) is a software licensing and delivery model in which access to the software is provided on a subscription basis, with the software being hosted on an external cloud infrastructure, rather than having it hosted on local servers [1]. Software-as-a-Service is usually accessed through the internet, with users logging into the system using a username and password. Instead of each customer having to install the software on his device, the customer is able to access the program on a web browser.

According to Vaeksthus, the main benefits of the SaaS business model include easy administration, automatic updates and patch management, easier collaboration, global accessibility and compatibility, as all users have access to the same version of software [2]. The preeminent disadvantages of Software-as-a-Service model refer to data security and delivery speed. Because the software is externally hosted, it is more vulnerable to be accessed by unauthorized parties, compared to internally hosted software.

The Software-as-a-Service model has been primarily adopted by IT and financial businesses and tech companies whose main purpose is selling innovative, digital products. The relative advantage, the organizational strategies and the business environment evolution are also key elements which determine the success of a SaaS business [3].

A sustainable SaaS business must be designed as a multi-function operating machine which builds the product. The decision makers must understand the global market and the competition very well and use technology to always be one step ahead. They are responsible for hiring the right people, creating a strong operational process and setting the right pricing in order to build a product which delivers value and is focused on the current and the future needs of customers.

\section{SEARCH ENGINE OPTIMIZATION FOR SAAS BUSINESSES}

According to Techopedia, a search engine is a program that allows Internet users to search for content via World Wide Web (WWW). The user enters keywords or key phrases into a search engine and receives a list of web content results in the form of websites, images, videos or other online data [4].

Though there are lots of search engines on Internet, Google is the most developed and popular search engine used worldwide. Its highly qualitative results and convenient response time recommend it. But because it is so popular, it is not used by individuals only, but also by businesses. Software-as-a-service companies depend even more on their rank in search engines, since the product they sell is digital. If in the past one had to go to the market place to purchase what he needed, today, with access to Internet, the customers are just at one click distance from what they want and the virtual market places are search engines, in our case Google. A reason why search engines like Google are so powerful is because they work based on keywords and 
thus are able to fulfill the needs of their users by giving them the best choices available on the Internet for a specific search.

Google uses complex algorithms to analyze websites and to decide which results come first in Google search. Content is very important, but yet not enough for businesses to rank high with their website. Search engine optimization (SEO) plays a core role in the ranking process, by maximizing the traffic which comes to a specific website from a search engine. In order to increase their visibility on Internet, the companies like SaaS businesses use technology and the expertise of professionals with required know-how to bring their site in the first line of searching. The higher they rank, the more traffic they will drive to their website and consequently the more customers will buy from them.

Google Analytics and Search Console are two premium tools offered by Google to companies which want to see how much traffic is driven to their website from Google searches. Semrush is another great tool which businesses can use to find who their competition on their valuable keywords is. By using complex tools, companies can increase the quantitative and qualitative dimensions of the traffic driven to their website.

Search engine optimization (SEO) begins with organizing the hierarchy of the website logically, by ensuring a smooth navigation on it. The following step is making sure the content is unique and useful for your readers, and the landing pages contain the valuable keywords. Creating accurate page titles and URLs descriptions and organizing the articles by offering good definitions and lists that can potentially become featured snippets on search engines comes next. Last but not least is checking whether the "description" meta-tag is used correctly, in order to rank higher on Google [5]. All these elements affect the ranking and implicitly the sales and profits of SaaS businesses.

\section{CASE STUDY - THE SUCCESSFUL STORY OF A SAAS BUSINESS: CANVA}

Canva is a Software-as-a-Service company which offers high-quality graphic design tools through their website and app. The tech start-up was launched in 2012 and it has its headquarters in Sydney, Australia. Their mission is to make design easy and fun even for non-designers.

According to Elaine N. Marieb [6], almost $50 \%$ of our brain is involved in visual processing. Canva anticipated the importance of visual content for businesses, and built a platform which makes the process of creating visuals accessible to everyone. The startup which values now $\$ 1$ billion [7] used the power of technology and search engines to become the no. 1 online design platform.

The aim of this study is to show how Canva leveraged search engine optimization to make their product known and loved by users all over the Globe.

The research method employed for this study is a user oriented approach that might seem rather empirical but is strategically considered for its very directness and applicability, as ultimately it proves highly general and any user friendly.

The steps of our research were as follows: first we prepared a list of keywords relevant for the business, in various languages. Then, introducing the keywords one by one in the search engine, we checked for the results returned. An analysis of the results was next conducted by noting the ranking returned for each keyword. 
The keywords that we considered relevant for Canva business and therefore worth searching by the Google search engine were as follows: 'brochure maker', 'card design', 'business card', 'greeting card design', 'flyer maker', 'invitation card', 'leaflet maker', 'poster' and 'presentation design'.

We first searched the keyword 'brochure maker' on different languages, to analyze how Canva optimized their website to appear in front of their competition in Google search in different countries. We explicitly show here forward, in the next three figures, some of the results returned for this keyword.

When building a digital product and wishing to sell internationally, it is essential that the website is well optimized especially in English, the most common language used on the Internet [8]. Canva made sure they appear on the first position in Google search for their most valuable keywords, including 'brochure maker'. As seen in the example below (Figure 1), Canva's brochure page appears right after Google Paid Ads:

Figure 1: Canva's top result by search key 'brochure maker'

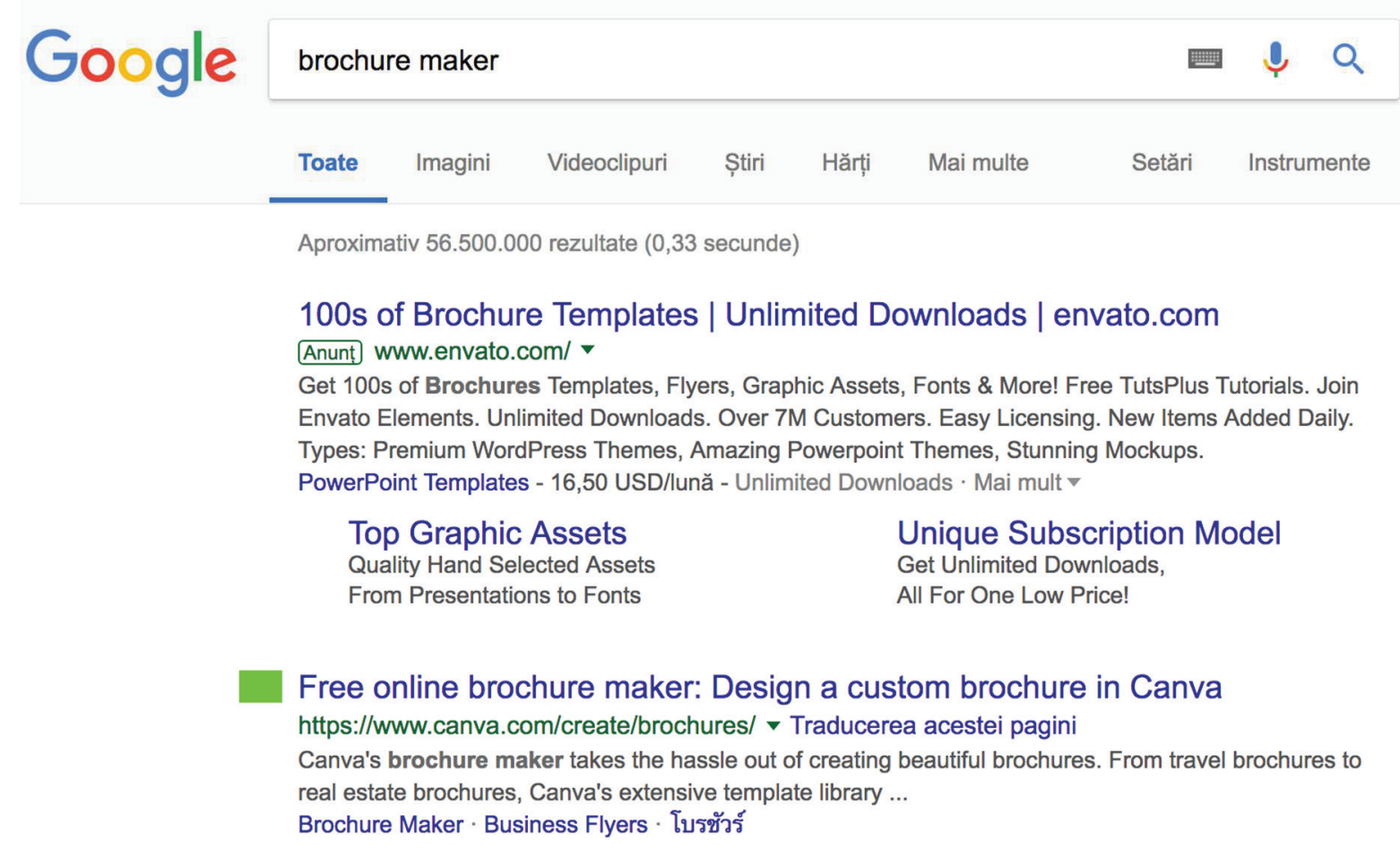

Source: own search and print screen as of 2018-11-23_19:31

Canva has translated their website in 28 languages, while the editor of the platform supports over 50 languages [9]. Because on average, the no 1 position in Google search has a clickthrough rate of $30 \%$, while the third position gets only $10 \%$ of the traffic from a Google search [10], Canva has worked hard to make sure they occupy the leading position in Google for as many language as possible.

They are on the first place in Google search in several languages, mainly in the most common languages of the Internet, such as Spanish, as seen in Figure 2: 
Figure 2: Canva's top result in Spanish

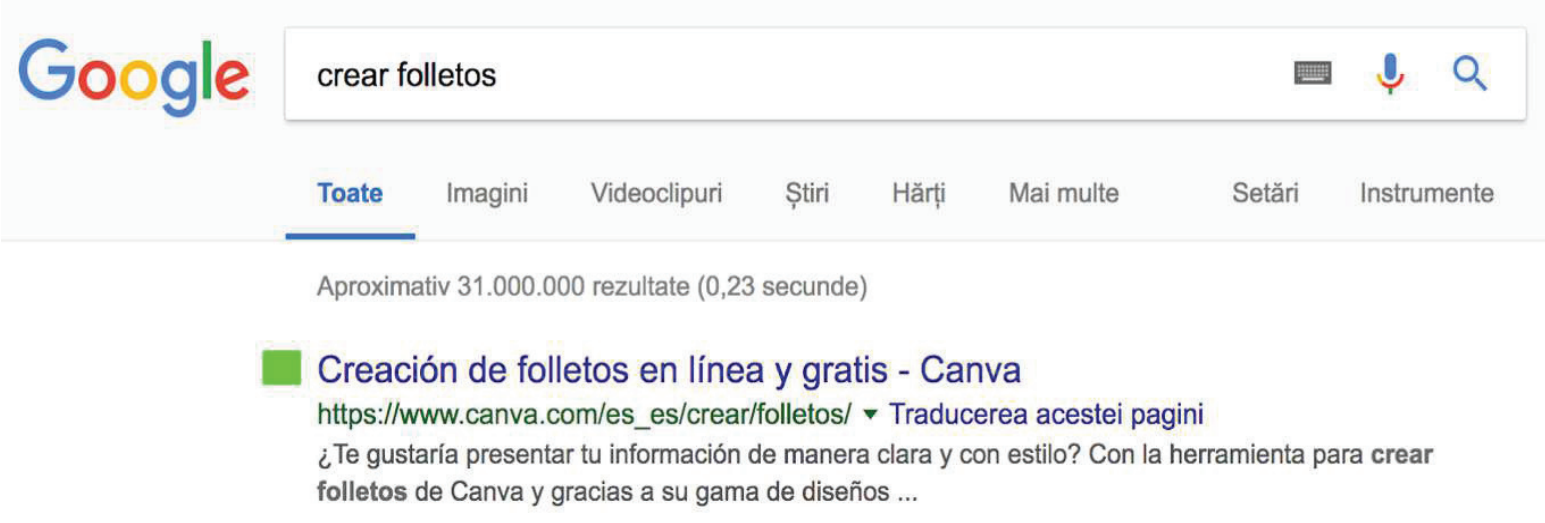

Source: own search and print screen as of 2018-11-23_19:32

However, though Canva ranks on the first place in Google search, there are some languages and keywords where the competition might be high for a specific keyword and Canva might lose some of their potential customers in front of their competitors which display paid ads for their valuable keywords. Figure 3 shows an example for German language, the search being made by the keyword 'create a brochure' (Deutsch: broschüreerstellen), where Canva's competitors Magglance and Envato appear in Google search before Canva, because they have paid ads on this keyword.

One thing that Canva could do would be to think to pay ads on some specific keywords, to make sure they don't lose new potential customers and implicit profits, in favor of their competition.

Figure 3: Canva's result in German, outranked by paid ads

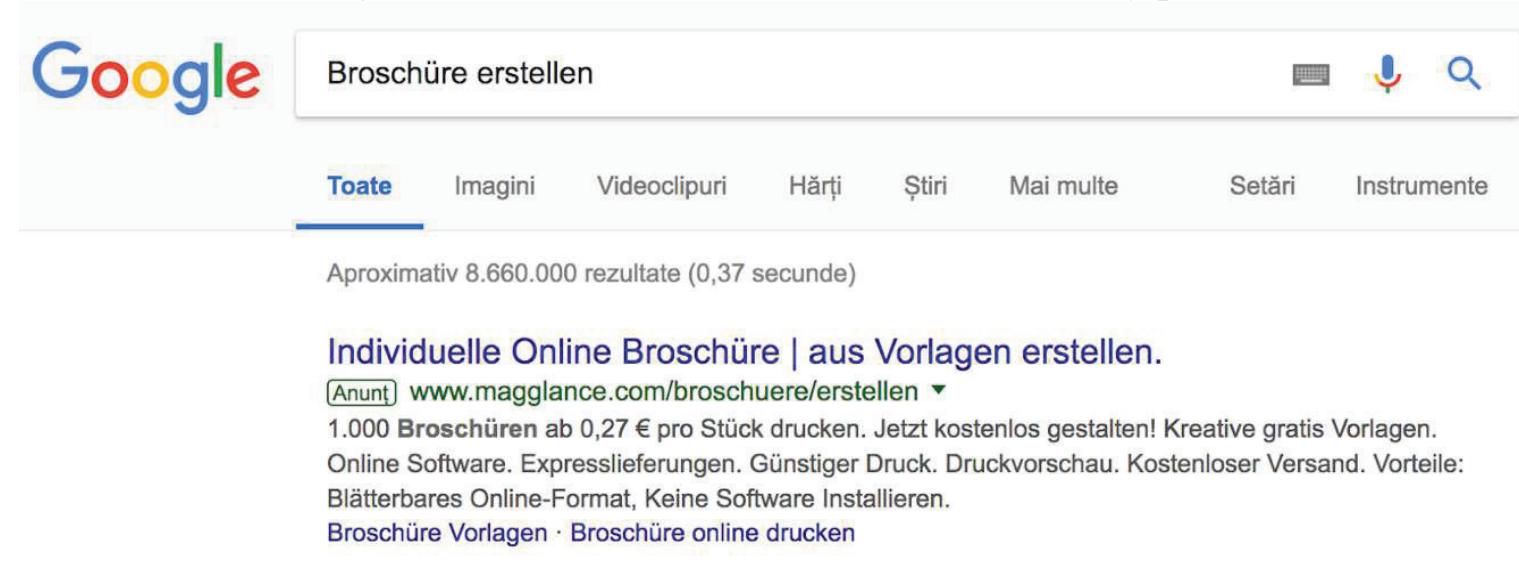

Top-Broschürenvorlagen 2018 | Unbegrenzte Downloads | envato.com

Anunt www.envato.com/ $\mathbf{v}$

Hunderte von Broschürenvorlagen, Flyern, Grafiken, Schriftarten \& mehr herunterladen! Über 7

Millionen Kunden. Treten Sie Elements bei. Kostenlose Tutorials. Einfache Lizenzierung.

Über Envato Elements · Kostenlose Files · Envato Elements Beitreten

Powerpoint-Vorlagen - 16,50 USD/lună - Unbegrenzte Downloads · Mai mult ₹

Dein kostenloser Online-Broschüren-Gestalter - Canva

https://www.canva.com/de_de/erstellen/broschuere/ • Traducerea acestei pagini

Mit dem Broschüren-Gestalter von Canva kannst du beeindruckende Broschüren mit professionell

entworfenen Layouts erstellen. Mit Drag \& Drop ziehst du ...

Source: own search and print screen as of 2018-11-24_15:15 
Next, we performed similar analyses for the other eight keywords, of relevance for the case study. The overall result is visually presented in the last two figures.

Out of the nine keywords searched, four ranked on the first position by Google search, three returned the result of a second position among the searches, and the other two situated Canva on position three, as seen in Figure 4.

Figure 4: Ranking by most relevant search keywords

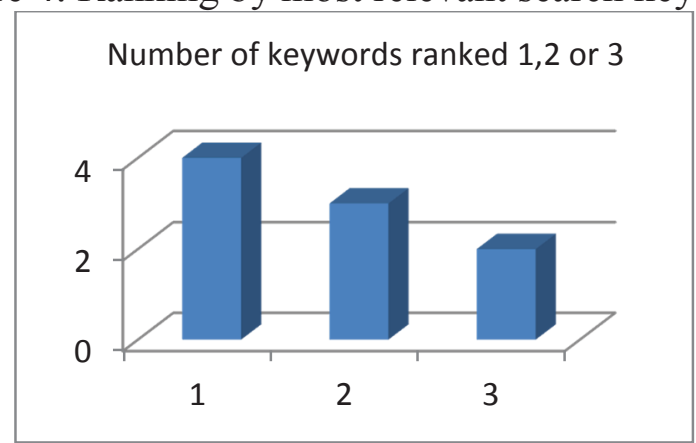

Source: own design by Excel data input and graphic generation

Thus, searches by the phrases 'brochure maker', 'card design', 'flyer maker' and 'presentation design' returned first rank results, while searches for 'leaflet maker', 'invitation cards' and 'poster' situated Canva on the second position. It came on the third place at the search by 'greeting card design' and by 'business card'. This classification is presented in Figure 5 below.

Figure 5: Results returned by each keyword

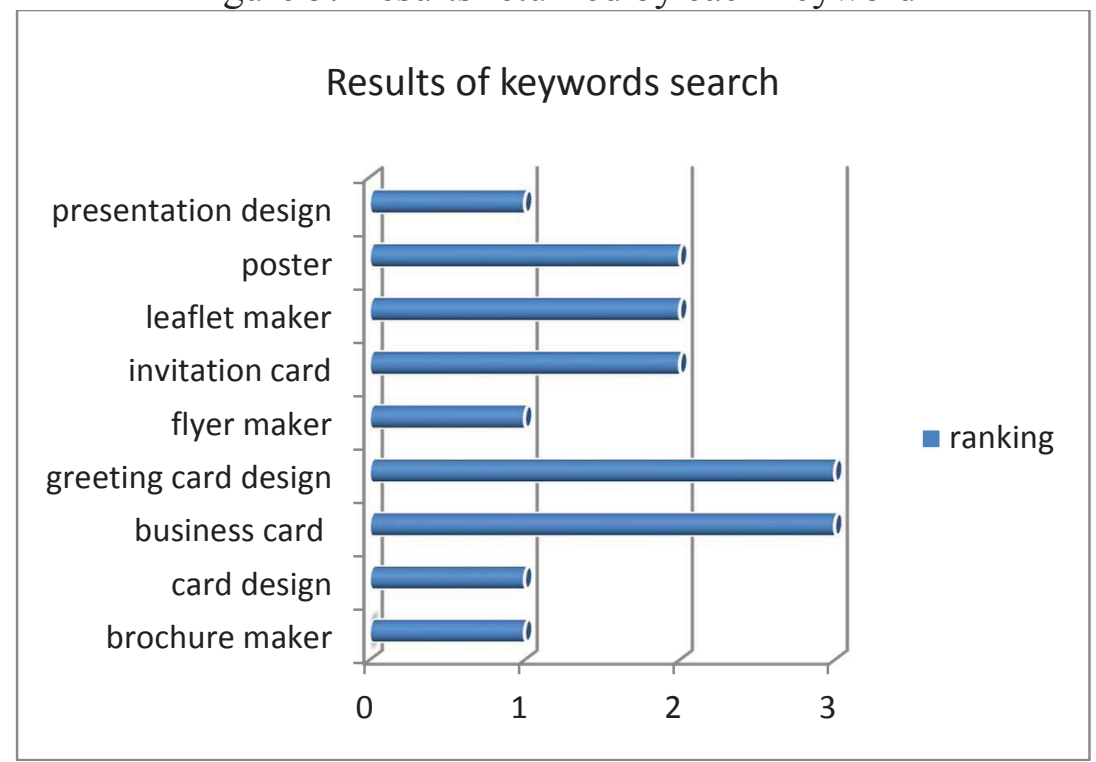

Source: own design by Excel data input and graphic generation

The results are in our view quite self-explanatory, considering the fact that, on one hand, for business cards, for instance, there ought to be other specialized applications, providing more professional templates and formal designs, and many companies offer products for and services of greeting cards own design, while, on the other hand, the most relevant words searched returned indeed the highest rank. 


\section{CONCLUSION}

In order to have a successful SaaS business you have to make sure you keep up with the development of technology and use it to be one step ahead of your competition, to build a good and useful product by meeting the present and future needs of your customers. It is quite obvious that the higher you rank within the search engines results, the more your business can grow, i.e. users can find you more straightforwardly, sales will go up and profits shall follow.

To stay competitive nowadays, it is of utmost importance for a business to build a strong website to showcase their product and to use search engine optimizations to rank higher and strengthen their position on the virtual market.

Many businesses can follow the model of good practices that can be seen with Canva and learn from them how to build a strategy if they want to go internationally. Optimizing their websites on different languages, by having in mind their targeted countries and the customers they want to sell to, would be a vital first step.

\section{REFERENCES}

[1] Software As A Service (SaaS) https://www.investopedia.com/terms/s/software-as-aservice-saas.asp\#ixzz5XCVtBRii

[2] A little book about SaaS - How to scale a SaaS startup; Vaeksthus Copenhagen, 4-6 https://startvaekst.dk/file/604001/saas.pdf

[3] Fariba Safari, Narges Safari, Alireza Hasanzadeh, (2015) "The adoption of software-as-aservice (SaaS): ranking the determinants", Journal of Enterprise Information Management, Vol. 28 Issue: 3, pp.400-422, https://doi.org/10.1108/JEIM-02-2014-0017)

[4] https://www.techopedia.com/definition/12708/search-engine-world-wide-web

[5] https://support.google.com/webmasters/answer/7451184?hl=en

[6] https://www.amazon.com/Human-Anatomy-Physiology-7th-Edition/dp/0805359095

[7] https://www.bloomberg.com/news/articles/2018-01-08/sequoia-backed-canva-becomesaustralia-s-only-tech-unicorn

[8] https://www.statista.com/statistics/262946/share-of-the-most-common-languages-on-theinternet/

[9] https://support.canva.com/account-basics/creating-a-canva-account/supportedlanguages/

[10] https://www.smartinsights.com/search-engine-optimisation-seo/seoanalytics/comparison-of-google-clickthrough-rates-by-position/ 